\title{
Online Survey of Reading Strategies (OSORS): Students' Online Reading in Academic Context
}

\author{
Zailani Jusoh $^{1^{*}}$ and Liza Abdullah ${ }^{2}$ \\ ${ }^{1}$ Universiti Sultan Zainal Abidin, Malaysia \\ ${ }^{2}$ International Islamic University Malaysia \\ *zailani@unisza.edu.my
}

Published online: 29 August 2016

To cite to this article: Zailani Jusoh and Liza Abdullah. 2015. Online survey of reading strategies (OSORS): Students' online reading in academic context. Malaysian Journal of Distance Education 17(2): 67-81. doi: 10.21315/mjde2015.17.2.5

To link to this article: http://dx.doi.org/10.21315/mjde2015.17.2.5

\begin{abstract}
Academic success greatly depends on the ability of students to capitalise the information available at their disposal through improved reading skills. However, the emergence of digital texts has transformed the nature of academic reading as online reading is reported to be different from traditional printed reading. As such, this paper which is based on a study conducted on students in a particular university in Malaysia, was written to investigate the extent of the use of strategies when reading online, in an academic setting and also to investigate whether differences in the use of the strategies between students in different field of studies exist. Findings suggest that students are all users of strategies and field of studies has no bearing on the type of overall strategies preferred. However, significant difference was found for support strategies. One of the implications is the need for class instruction in raising students' awareness on the importance of varied usage of strategies when reading materials online.
\end{abstract}

Keywords: online survey of reading strategies (OSORS), online reading strategies, university students, academic discipline

\section{Introduction}

Reading plays a pivotal role in one's education as through reading, knowledge is acquired and thus making it a critical component across all disciplines. In fact, all formal education are rely on this skill to progress. It accounts for a great component of students' academic life. Reading is even 
more critical for language learners, especially in English, as it is the most effective and viable means of acquiring a foreign language (Dreyer, 1998). In fact, its importance is highlighted by Levine, Ferenz and Reves (2000: 1) who posited that:

'the ability to read academic texts is considered one of the most important skills that university students of English as a second language (ESL) and English as a foreign language (EFL) need to acquire.'

Although reading is a major component in many academic disciplines, it is a very complex skill to master. The mastery of reading is even made more complicated with the migration of text from printed to online, whereby many more information are available electronically, whether through electronic texts or the Internet. The proliferation of technology has actually transformed the nature of this literacy aspect. Now the internet has entered almost every educational institution at every corner of the world. Malaysia is without exceptions. Although the use of technology, the Internet especially, is relatively new to the education system in Malaysia, more and more schools and higher learning institutions are adopting the technology into their curricula as it is said to offer a lot of benefits to teaching and learning processes.

Despite the numerous advantages, many are slightly more cautious of the impacts the Internet has on learners. As Coiro et al. (2003: 51) highlighted, 'electronic texts introduce new supports as well as new challenges that can have an impact on an individual's ability to comprehend what he or she reads. Reading electronic texts is different from printed texts as the strategies involved in processing the information online texts are not the same, although some are applicable to both media, while others are more exclusive for online comprehension (Spiro, 2004; Coiro and Dobler, 2007).

The differences require serious attention from educators as 'comprehension processes and decoding processes must be learned and taught so that these changes can be reflected in readers' and authors' strategies for comprehension and response' (Kinzer and Leander, 2007: 547). Therefore, students in the digital era do not only have to adjust their reading behaviour from traditional to digital texts, but they also have to be taught necessary digital literacy skills to help them comprehend and cope 
with online texts well (Gilbert, 2014). If students are to take full advantage of the informational possibilities provided by the Internet, then it is essential to develop their digital literacy skills and strategies. They need new skills to face this new challenge (i.e., key word searching, selection or organisation) that will help them to manage these rich information resources.

In a meta-analysis study of 80 research articles that focused on comprehension and technology, only three focused on the Internet (Coiro et al., 2003). This gap in the research literature means that many educators may not equip their students with the comprehension skills and strategies they need to capture the opportunities for reading that are available through the Internet.

Many studies have been conducted on the reading strategy usage among learners of English when undertaking academic tasks, but most focused on traditional printed texts. There is not much research on online reading strategy usage, especially those investigating students in different academic fields.

\section{Literature review}

The interest in understanding more on learning strategies started in the $70 \mathrm{~s}$ when researchers discovered the importance of shifting the emphasis from teachers and teaching process to learners and learning process. Since then a lot of studies have been conducted to deepen our understanding in the area of metacognitive strategies.

\section{Strategy Use and Academic Disciplines}

Academic disciplines have been shown to have some influence on the strategy used. Alexander and Filler (1976) noted that although strategies are important in reading comprehension, the appropriateness of some strategies depends on the domains of studies. Due to the nature of the area of studies, students who enrolled in different programmes will study different subjects which required them to use different language skills and read different materials and do different tasks. Therefore, students need to apply different approach in their way of reading. Although researchers are aware of the existence of a relationship between materials, tasks and 
strategy usage, studies examining the influence of academic disciplines on strategy usage are very limited. Those that were done have produced mixed findings.

Oxford and Nyikos (1989) conducted a study to investigate factors affecting the use of language learning strategies among university students. The study utilised Oxford's (1990) strategy in language learning (SILL) which contains several components. One interesting finding from the study was that the metacognitive strategy usage appeared to be significantly different between the majors. Metacognitive strategies are used more frequently by students in Humanities, Social Science and Education compared to those in Technical and Business fields.

Similarly, Peacock and Ho (2003) studied learning strategies of those majoring in Science, Mathematics, Engineering, Building, Business, Computing, English, Primary Education in Hong Kong. The study indicated that different academic disciplines do affect the students' preference for certain learning strategies. As an example, overall strategies were more commonly used by students majoring in English, but least used by those study in Computing. In terms of individual category, English students employed more cognitive, metacognitive and social strategies than those in other majors.

Ghafournia and Afghari (2013), using the same instrument, compared the strategies used by postgraduates in different fields of studies in Iran. They found that significant differences were noted among students in different academic disciplines (Engineering, Basic Science and Social Science) in overall, direct and indirect strategies. Another interesting finding is that students in Social Science were the highest users of strategies, while students in Engineering were the least.

In a local context, a similar study (Nik Yusoff, 2008) has produced similar but less obvious results. The study, which was also conducted on university students in the English for Academic Purpose (EAP) classes showed no significant difference in the frequency of the strategy usage between the majors although skilled readers in Business and Technical programmes have used significantly more strategies compared to skilled readers in Humanities and Social Science. 


\section{Reading Strategies and English Language Learning}

Studies on the importance of employing effective reading strategies in learning English language in different environments are well documented. For instance, Mokhtari and Reichard (2004) compared strategies utilised by readers in two different learning environments, in the USA and Morocco. Their study indicated that although the environments differed, similar patterns of usage were reported although the types of strategies preferred varied in both settings. Similarly, Karbalaei (2010) replicated the study of the English as a Foreign Language (EFL) (Iranian) and the English as a Second Language (ESL) (Indian) college students. The findings indicated that both groups demonstrated similar patterns of strategy usage. Both groups reported to use problem solving strategies at the most. Nonetheless, Indian readers were mentioned using strategies more frequently and more widely. These studies indicated that despite learning English in different socio-cultural settings, students were the all users of strategies in one way or another. However, both studies were conducted on traditional printed reading, which are said to differ greatly from online reading which is more challenging to do.

\section{Metacognitive Strategies and Online Reading}

Despite the popularity of online reading, only a limited number of studies have been conducted on the relationship between strategy usage and online reading performance among students learning English.

One of the first studies conducted on online reading was by Anderson (2003) who explored strategies usage in ESL and EFL context. Adapting an instrument, called Survey of Reading Strategies (SORS), designed by Mokhtari and Sheorey (2002), he developed a new instrument, Online Survey of Reading Strategies (OSORS), which is used to measure online reading strategies. The study, however, did not find significant differences in the use of the strategies between these two groups. In fact, there were more similarities, especially in the use of global and support strategies rather than differences. The only difference is in terms of frequency of problem solving strategies which is reported to be more among the EFL students. However, the study focused on learning environment rather than academic discipline. 
In an EFL context, Pookcharoen (2009) conducted a study on online reading strategy of Thai students. The study used a mixed method (OSORS and verbal protocol and interview) compared to the use of online reading strategy among proficient and non proficient readers in academic setting. It was found that language proficiency plays important roles in both frequency and quality of the strategy used. However, the study investigated a different variable that is the language proficiency. In addition, a more recent study by Omar (2014) sought to investigate the online reading strategies among elder postgraduates in Libya in general without focusing on any particular demographic variables. Her study found that they were moderate users of strategies. Problem solving strategies were most frequently used while support strategies were the least used.

In Malaysia, exposure to the Internet in education is still relatively new as compared to other parts of the world. Therefore, little is known about how Malaysian college students have been affected by the new digital literacy. Though a number of studies (eg. Nor Shahriza and Amelia, 2007) have been carried out to investigate how digital literacy has affected students in Malaysia, they merely reported the perception of students regarding their reading habits. Other studies (Tan and Liaw, 2009; Abdul Rashid, Chew and Muhammad Kamarul, 2006) investigate the effects of online strategy awareness training on secondary school students. These studies have found that students have benefited from the training given as they are more exposed to the different variety of strategies available. So far, only a study by Nor Fazlin, Saadiyah and Nadzrah (2011) was conducted to measure students' strategy use in a Malaysian university. Their study found that students used global strategies at the most and support strategies at the least. However, their study only focused on students in two different semesters rather than across academic disciplines.

Although the literature cited above have shed some light into online reading process, much need to be done especially for elder students, to enable practitioners to paint a clearer picture on how students in college approach academic reading online. It is important to find out the strategic usage as studies have indicated that the elder the adults are and the more proficient the readers are, the more essential metacognitive strategies are for reading comprehension (Mokhtari and Sheorey, 2002). Furthermore, thus far no known studies have been conducted in investigating how 
students in different field of studies read online materials although those studying printed text reading are abundant. Thus, this study is warranted to fill the gap between the use of strategies in online reading and academic reading.

\section{Research Objectives and Research Questions}

The purpose of this study has two folds. First, it attempts to investigate the online reading process of students in an academic setting when reading online texts. The second purpose is to explore whether differences exist between the use of strategies among students from two different faculties. The primary research questions are as follows:

1. What are the students' strategies when reading online materials?

2. Are there any differences in the choice of strategy among students in two different academic disciplines?

\section{Research Methodology}

\section{Samples}

Samples for this study were drawn from students in two faculties: Faculty of Languages and Communication - FBK (Humanities-based) and Faculty of Information Technology - FIT (IT-based). The students were in their semester three of their four-year degree programmes in UniSZA.

A total of 155 students were invited to participate, however, only 102 volunteered to get involved. Table 1 indicated the breakdown of the participants based on faculty, gender and language proficiency level. As shown in the table, more than half of the students $(63 \%)$ were from FBK and female represented $73 \%$ of the respondents.

\section{Instrumentation}

The questionnaire used in the study consists of two sections: 1) demographic information and 2) online reading strategies survey. The first section was designed to elicit information pertaining to the respondents' background information. The second section, on the other hand, dealt with the students' reported strategy usage when reading online texts. It consisted of items adapted from an instrument called OSORS 
which was developed by Anderson (2003). The instrument was an adapted version of Survey of Reading Strategies (SORS) (Sheorey and Mokhtari, 2002). The original instrument, which was made up of three sub constructs contained 38 statements used to reflect students' metacognitive online reading strategies. However, for the purpose of the study, two items were excluded as they were found to be irrelevant based on a pilot study conducted. The three categories are global reading strategies - GLOB (16 items), problem solving strategies - PROB (11 items) and support reading strategies - SUP (9 items). OSORS consists of 5-point Likert scale (from $1=$ never to $5=$ always). The mean scores from OSORS were divided into three groups based on Oxford's (1990) classification: 1) 1-2.33 (low usage), 2) 2.34-3.66 (medium usage), and 3) 3.67-5.00 (high usage). The reliability index (Cronbach's alpha) of OSORS for this study was calculated and found to be 0.89 for the overall survey. In other words, the instrument is said to have good internal consistency.

Table 1 Demographic information of the respondents

\begin{tabular}{lccc}
\hline Category & & $\mathrm{N}$ & Percentage \\
\hline Gender & & & \\
\hline & Male & 28 & 27.5 \\
& Female & 74 & 72.5 \\
\hline Faculty & & & \\
\hline & FBK & 64 & 62.7 \\
& FIT & 38 & 37.3 \\
\hline Language proficiency & & & \\
\hline & Low & 52 & 51.0 \\
& High & 50 & 49.0 \\
\hline
\end{tabular}

\section{Analysis of Results}

The following section discusses results from the data analysis. The analysis was performed based on the research questions the study sought to answer.

\section{Research Question 1}

What are the students' strategies when reading online materials? 
In answering the first research question, three descriptive analyses were conducted. The first was to report strategies based on level of usage while the second analysis was based on the category of strategies and the last analysis dealt with the most and least popular individual strategies.

\section{Reported Strategies by Usage Level}

Using Oxford's (1990) classification, the 36 strategies were divided into three groups according to their frequency of usage. They are low usage (means of 1-2.33), medium (2.34-3.49), high (3.5-5.00). Table 2 reported the strategies based on their usage.

Table 2 Strategies by usage level

\begin{tabular}{lcc}
\hline Type of usage & No of strategies & $\%$ \\
\hline High & 16 & 44 \\
Medium & 20 & 56 \\
Low & 0 & 0 \\
\hline
\end{tabular}

There were $16(44 \%)$ out of the total 36 online reading strategies that belong to this high category based on the mean of 3.68 and above. This means that students in UniSZA usually or always use strategies when reading online. Meanwhile the means of the remaining $20(56 \%)$ strategies fell into medium category. This indicates that students sometimes use strategies when reading online. Surprisingly, for the last category (low strategy usage), no strategies were reported to belong to this category. What this suggests is that, all participants, either in high or medium category usage, were the users of strategies when reading online.

\section{Reported Strategy by Category}

Table 3 illustrates the means of usage based on the sub-categories of the strategies. Among the three types of strategies investigated, problem solving was reported to have the highest score (mean=3.77, $\mathrm{SD}=0.479$ ) while support strategies the lowest (mean $=3.386, \mathrm{SD}=0.608)$. This shows that students used problem solving strategies slightly more frequently than any other type of strategies. 
76 Malaysian Journal of Distance Education 17(2), 67-81 (2015)

Table 3 Reported strategy usage by category

\begin{tabular}{lccc}
\hline Category & N & Mean & SD \\
\hline Global (GLOB) & 102 & 3.67 & 0.438 \\
Problem Solving (PROB) & 102 & 3.77 & 0.478 \\
Support (SUP) & 102 & 3.39 & 0.608 \\
\hline
\end{tabular}

\section{Reported Strategy based on Individual Strategies}

In terms of individual strategies, Table 4 depicts the top seven and the bottom seven strategies as reported by the participants. It is worth noting that among the top seven strategies, five are from problem solving while four of the bottom seven strategies belong to support strategies. This indicates that problem solving strategies are the most commonly used strategies while the least used are support strategies. The most popularly used strategy was 're-reading to increase understanding' while the least used was 'translating from English to Bahasa Malaysia'.

Table 4 Top seven and bottom seven reading strategies

\begin{tabular}{|c|c|c|}
\hline & Top seven strategies & Bottom seven strategies \\
\hline 1 . & $\begin{array}{l}\text { When on-line text becomes } \\
\text { difficult, I re-read it to increase my } \\
\text { understanding (PROB) }\end{array}$ & $\begin{array}{l}\text { 30. I print out a hard copy of the on-line text, } \\
\text { then underline or circle information to } \\
\text { help me remember it (SUP) }\end{array}$ \\
\hline 2. & $\begin{array}{l}\text { I adjust my reading speed } \\
\text { according to what I am reading on- } \\
\text { line (PROB) }\end{array}$ & $\begin{array}{l}\text { 31. I can distinguish between fact and } \\
\text { opinion in on-line texts (PROB) }\end{array}$ \\
\hline 3. & $\begin{array}{l}\text { When reading online, I decide } \\
\text { what to read closely and what to } \\
\text { ignore (GLOB) }\end{array}$ & $\begin{array}{l}\text { 32. I ask myself questions I like to have } \\
\text { answered in the on-line text (SUP) }\end{array}$ \\
\hline 4. & $\begin{array}{l}\text { I try to guess what the content of } \\
\text { the on-line text is about when I } \\
\text { read (GLOB) }\end{array}$ & $\begin{array}{l}\text { 33. I critically analyse and evaluate the } \\
\text { information presented in the on-line text } \\
\text { (GLOB) }\end{array}$ \\
\hline 5 . & $\begin{array}{l}\text { I try to get back on track when I } \\
\text { lose concentration (PROB) }\end{array}$ & $\begin{array}{l}\text { 34. I read pages on the Internet for fun } \\
\text { (GLOB) }\end{array}$ \\
\hline 6. & $\begin{array}{l}\text { When on-line text becomes } \\
\text { difficult, I pay closer attention to } \\
\text { what I am reading (PROB) }\end{array}$ & $\begin{array}{l}\text { 35. I take notes while reading on-line to help } \\
\text { me understand what I read (SUP) }\end{array}$ \\
\hline 7. & $\begin{array}{l}\text { When I read online, I guess the } \\
\text { meaning of unknown words or } \\
\text { phrases (PROB) }\end{array}$ & $\begin{array}{l}\text { 36. When reading online, I translate from } \\
\text { English into B. Melayu (SUP) }\end{array}$ \\
\hline
\end{tabular}




\section{Research Question 2}

Are there any differences in students' choice of strategy by academic disciplines?

The data were analysed inferentially, namely using an independent sample $t$-test.

\section{Strategies by Faculties}

The assumptions of the $t$-test, normal distribution and equality of variances, were met. Both the Shapiro-Wilk normality test $(0.082, p>0.05)$ and Levene's test $(0.862, p>0.05)$ showed no significance.

An independent samples $t$-test was conducted to compare the reading strategies used by students in two different faculties (FBK and FIT). There were no significant differences in the overall strategies utilised by students in FIT (mean=3.64, SD=0.45), and students from FBK (mean=3.62, $\mathrm{SD}=0.39) ; t(100)=-0.25, p=0.84)$.

When comparing individual subsection, no significant differences were observed in two of the three categories. The only significant difference between FBK and FIT readers appears in the use of support strategies. FIT students reported a higher use of support strategies (mean $=3.63, \mathrm{SD}=0.67$ ) than did the students from FBK (mean=3.24, SD=0.52), $t(100)=-2.32$, $p=0.024$ ). The magnitude of the difference in the means (mean difference $=0.308$ ) was, however small (eta square $=0.051$ ). Table 5 provides detailed information regarding the differences. 
Table 5 Reported strategy usage by academic disciplines

\begin{tabular}{lcccccc}
\hline Category & Faculty & N & Mean & SD & $t$ & Sig. (2-tailed) \\
\hline Overall & FBK & 64 & 3.619 & 0.388 & & \\
& FIT & 38 & 3.643 & 0.445 & -0.205 & $0.839(\mathrm{~ns})$ \\
Global & FBK & 64 & 3.721 & 0.445 & & \\
\multirow{4}{*}{ Problem Solving } & FIT & 38 & 3.582 & 0.422 & 1.094 & $0.279(\mathrm{~ns})$ \\
& FBK & 64 & 3.781 & 0.358 & & \\
Support & FIT & 38 & 3.741 & 0.645 & 0.283 & $0.778(\mathrm{~ns})$ \\
& FBK & 64 & 3.239 & 0.524 & & \\
& FIT & 38 & 3.632 & 0.672 & -2.322 & $0.024^{*}$ \\
\hline
\end{tabular}

*sig at $p=0.05$

\section{Conclusions and Recommendations}

OSORS was used to collect information pertaining to the use of strategies by students in two different faculties in UniSZA. OSORS contains a variety of strategies that readers normally use when reading online. The study has indicated that students, regardless of their field of studies, are all frequent users of strategies. It is consistent with other studies (Anderson, 2003; Pookchareon, 2009) which indicated that all second language learners use strategies in aiding them with reading comprehension. However, an interesting finding of the most popular group of strategies was problem solving which confirms the statement regarding the nature of online reading. Leu et al. (2004) mentioned that online reading is a problem solving process, whereby students have to go back and forth in making sense of the materials. This explains the reasons behind the popularity of problem solving strategies among students. The findings provide further support for other studies (Omar, 2014; Taki and Soleimani, 2012). Conversely, majority of the least popular strategies belong to support strategies. The unpopularity of this group of strategies, according to Taki and Soleimani (ibid), is because they are time consuming to apply. The findings are consistent with the ones produced by Nor Fazlin, Saadiyah and Nadzrah (2011).

When academic disciplines were compared, overall there is no significant difference in the strategy used. The finding concurs with Nik Yusoff's (2008) which concluded that field of studies did not have impact on the 
strategy used although other studies on printed texts (Oxford and Nyikos, 1989; Peacock and Ho, 2003; Ghafournia and Afghari, 2013) have found otherwise. However, in terms of individual category, significant difference did exist in the use of support strategies in which students enrolling in Information Technology course were reported to be using more support strategies. Although support strategy was found to be the least popular among students in general, this particular category of strategy showed significant difference between the two groups of students. The fact that IT students use more support strategy is well understood as they are more well-versed and familiar with the internet features and tools such as online dictionaries and references.

Nonetheless, the findings from this study have to be viewed in light of its limitations. One of the shortcomings is that, OSORS is a 'self-report' instrument. Thus, its use in itself is subject to scrutiny. In fact, Sheorey and Mokhtari (2001: 8) has cautioned researchers on the use of a selfreport questionnaire by stating that 'one cannot tell with absolute certainty from the instrument alone whether students actually engage in the use of strategies as reported'.

Despite its limitations, this study has several pedagogical implications. One of which is, the importance of creating awareness of the existence of various strategies for successful comprehension. In fact, some strategies, especially the ones that are less frequent used should be taught in classroom as some studies have indicated that class instruction in strategic reading has been found to improve comprehension (Tan and Liaw, 2009; Abdul Rashid, Chew and Muhammad Kamarul, 2006).

Since research on online reading is still considered in its infancy, a lot more needs to be done in order to fully understand the things students are actually doing when surfing for information online. One area to be explored is examining the difference in strategies used when reading both online and off line texts. 


\section{References}

Abdul Rashid Mohamed, J. Chew and Muhammad Kamarul Kabilan. 2006. Metacognitive reading strategies of good Malaysian Chinese learners. Malaysian Journal of ELT Research 2: 21-41.

Alexander, J. and R. Filler. 1976. Attitudes and reading. Newark, DE: International Reading Association.

Anderson, N. 2003. Scrolling, clicking and reading English: Online reading strategies in a second/foreign language. The Reading Matrix 3(3): November 2003.

Coiro, J. and E. Dobbler. 2007. Exploring the online reading comprehension strategies used by 6th grade skilled readers to search for and locate information on the Internet. Reading Research Quarterly 42: 214-257. http://dx.doi.org/10.1598/ RRQ.42.2.2

Coiro, J., M. Knobel, C. Lankshear and D. Leu. eds. 2003. Handbook of research on new literacies. Mahwah, NJ: Erlbaum.

Dreyer, C. 1998. Improving students' reading comprehension by means of strategy instruction. Journal for Language Teaching 31: 18-29.

Ghafournia, N. and A. Afghari. 2013. Exploring the relationship between learning strategies, academic disciplines and reading comprehension test performance. Iranian Journal of Applied Linguistics (IJAL) 16(2): 21-51.

Gilbert, J. 2014. Exploring ESL students' perceptions of their digital reading skills. EdD diss., University of Nottingham.

Karbalaei, A. 2010. A comparison of the metacognitive reading strategies used by EFL and ESL readers. The Reading Matrix 10(2): 165-180.

Kinzer, C. K. and K. M. Leander. 2007. Reconsidering the technology/language arts divide: Electronic and print-based environments.

Leu, D. J, C. K. Kinzer, J. L. Coiro and D. W. Cammack. 2004. Towards a theory of new literacies emerging from the internet and other information and communication technologies. In Theoretical models and processes of reading, eds. R. B. Ruddel and N. J. Unrau, 1570-1613. Delaware: International Reading Association.

Levine, A., O. Ferenz and T. Reves. 2000. EFL academic reading and modern technology: How can we turn our students into independent critical readers? TESL-EJ 4(4): A-1. http://www.tesl-ej.org/ej16/a1.html.

Mesgar, M., Nadzrah Abu Bakar and Zaini Amir. 2012. Online metacognitive reading strategies used by postgraduate ESL readers of academic texts. International Journal of Asian Social Science 2(10): 1779-1794.

Mokhtari, K. and C. Reichard. 2004. Investigating the strategic reading process of first and second language readers in two different cultural contexts. System 32: 379 394. http://dx.doi.org/10.1016/j.system.2004.04.005

Mokhtari, K. and R. Sheorey. 2002. Measuring ESL students' awareness of reading strategies. Journal of Developmental Education 25(3): 2-10.

Nik Yusoff, N. S. 2008. The Role of metacognitive strategies in second language reading research. In Reading in a second language: The Malaysian context, eds. Z. Zainal and F. Mohamad Nor. Shah Alam: UPENA. 
Nor Fazlin Mohd Ramli, Saadiyah Darus and Nadzrah Abu Bakar. 2011. Metacognitive online reading strategies of adult ESL learners using a learning management system. Theory and Practice in Language Studies 1(3): 195-204. http://dx.doi.org/10.4304/tpls.1.3.195-204

Nor Shahriza Karim and Amelia Hasan. 2007. Reading habits and attitudes in digital age: Analysis of gender and academic program differences in Malaysia. The Electronic Library 25(3): 285-298. http://dx.doi.org/10.1108/ 02640470710754805

Omar, N. A. 2014. Online metacognitive reading strategies use by postgraduate Libyan EFL students. World Academy of Science, Engineering and Technology International Journal of Social, Behavioral, Educational, Economic, Business and Industrial Engineering 8(7). http://waset.org/publications/9998887.

Oxford, R. L. and J. Burry-Stock. 1995. Assessing the use of language learning strategies worldwide with the ESL/EFL version of the strategy inventory for language learning (SILL). System 23(1): 1-23. http://dx.doi.org/10.1016/0346251X(94)00047-A

Oxford, R. L. and M. Nyikos. 1989.Variables affecting choice of language learning strategies by university students. The Modern Language Journal 73(3): 291300. http://dx.doi.org/10.1111/j.1540-4781.1989.tb06367.x

Oxford, R. L. 1990. Language learning strategies: What every teacher should know. Boston, MA: Heinle and Heinle.

Peacock, M. and B. Ho. 2003. Student language learning strategies across eight disciplines. International Journal of Applied Linguistics 13: 179-200. http://dx.doi.org/10.1111/1473-4192.00043

Pookcharoen, S. 2009. Metacognitive online reading strategies among Thai EFL university students. PhD diss., Indiana University, USA.

Sheorey, R. and K. Mokhtari. 2001. Differences in the metacognitive awareness of reading strategies among native and non-native speakers. System 29(4): 431-449. http://dx.doi.org/10.1016/S0346-251X(01)00039-2

Spiro, R. J. 2004. Principled pluralism for adaptive flexibility in teaching and learning. In Theoretical models and processes of reading. 5th ed. eds. R. B. Ruddell and N. Unrau, 654-659. Newark, DE: International Reading Association.

Taki, S. and H. Soleimani. 2012. Online reading strategy use and gender differences: The case of Iranian EFL learners. Mediterranean Journal of Social Sciences 3: 173-184.

Tan, K. H. and M. L. Liaw. 2009. Empowering Malaysians to read online. European Journal of Social Sciences 8(2): 360-371. 